\title{
Targeting Hif1a rescues cone degeneration and prevents subretinal neovascularization in a model of chronic hypoxia
}

\author{
Maya Barben ${ }^{1,2}$, Christian Schori ${ }^{1,3}$, Marijana Samardzija $^{1 *+}$ (D) and Christian Grimm ${ }^{1,2,3+}$
}

\begin{abstract}
Background: Degeneration of cone photoreceptors leads to loss of vision in patients suffering from age-related macular degeneration (AMD) and other cone dystrophies. Evidence, such as choroidal ischemia and decreased choroidal blood flow, implicates reduced tissue oxygenation in AMD pathology and suggests a role of the cellular response to hypoxia in disease onset and progression. Such a chronic hypoxic situation may promote several cellular responses including stabilization of hypoxia-inducible factors (HIFs).
\end{abstract}

Methods: To investigate the consequence of a chronic activation of the molecular response to hypoxia in cones, von Hippel Lindau protein (VHL) was specifically ablated in cones of the all-cone $\mathrm{R} 1 \mathrm{~W}$; $\mathrm{Nr}_{\mathrm{r}}{ }^{-}$mouse. Retinal function and morphology was evaluated by ERG and light microscopy, while differential gene expression was tested by real-time PCR. Retinal vasculature was analyzed by immunostainings and fluorescein angiography. Two-way ANOVA with Šídák's multiple comparison test was performed for statistical analysis.

Results: Cone-specific ablation of Vh/ resulted in stabilization and activation of hypoxia-inducible factor 1A (HIF1A) which led to increased expression of genes associated with hypoxia and retinal stress. Our data demonstrate severe cone degeneration and pathologic vessel growth, features that are central to AMD pathology. Subretinal neovascularization was accompanied by vascular leakage and infiltration of microglia cells. Interestingly, we observed increased expression of tissue inhibitor of metalloproteinase 3 (Timp3) during the aging process, a gene associated with AMD and Bruch's membrane integrity. Additional deletion of Hifla protected cone cells, prevented pathological vessel growth and preserved vision.

Conclusions: Our data provide evidence for a HIF1A-mediated mechanism leading to pathological vessel growth and cone degeneration in response to a chronic hypoxia-like situation. Consequently, our results identify HIF1A as a potential therapeutic target to rescue hypoxia-related vision loss in patients.

Keywords: Retinal degeneration, Age-related macular degeneration, Cone photoreceptors, Hypoxia, HIF1, VHL, Mouse model

\section{Background}

Age-related macular degeneration (AMD) is the leading cause of visual impairment in the elderly population in industrialized nations [1-3]. Due to the degeneration of photoreceptors in the cone-rich macula and/or the ingrowth of blood vessels, patients suffering from AMD lose central, high acuity vision [4-6]. While there is no therapy available for geographic atrophy (dry AMD), the

* Correspondence: marijana.samardzija@usz.uzh.ch

${ }^{\dagger}$ Equal contributors

${ }^{1}$ Laboratory for Retinal Cell Biology, Department of Ophthalmology, University Hospital Zurich, University of Zurich, Zurich, Switzerland Full list of author information is available at the end of the article neovascular (wet) form of AMD is treated by vascular endothelial growth factor (VEGF)-targeting therapies to slow disease progression [7-9]. Choroidal neovascularization $(\mathrm{CNV})$ defines the classic form of neovascular AMD and is characterized by the ingrowth of blood vessels from the choroid to the subretinal space $[6,10]$. Retinal angiomatous proliferation (RAP) has been described as an additional, distinct form of neovascular AMD [11]. In RAP, also known as deep retinal vascular anomalous complexes, vessels originate not from the choroid but from the deep retinal plexus in the inner retina and extend into the photoreceptor layer and the subretinal space $[12,13]$. 
AMD is a multifactorial disease. Besides genetic and environmental risk factors $[5,14,15]$, tissue hypoxia and changes in retinal blood flow have been implicated in its etiology [16-20]. Oxygen supply to photoreceptors in the eyes of elderly people may be impaired due to an age-dependent reduction of choroidal blood flow [21, 22] and accumulation of drusen [23]. Choroidal ischemia in dry AMD [24, 25] and decreased choroidal blood volume in AMD [26] further support the hypothesis that hypoxia might be implicated in disease development and progression. The retina is considered as one of the most metabolically active tissues and is therefore highly vulnerable to changes in oxygen tension $[17,27]$. In conditions of reduced oxygen supply (hypoxia), molecular responses are activated with hypoxia-inducible factor 1 (HIF1) playing a key regulatory role for adapting the cell/tissue to the new condition. Heterodimeric HIF1 proteins are composed of an oxygen-labile $\alpha$-subunit and a constitutively expressed $\beta$-subunit [28]. Under normoxic conditions, HIF1A is hydroxylated by prolyl hydroxylase domain (PHD) proteins. This promotes the interaction with the von Hippel-Lindau (VHL) ubiquitin E3 ligase complex leading to ubiquitination and rapid degradation of hydroxylated HIF1A by proteasomes. Under hypoxic conditions, hydroxylation of HIF1A is reduced. Hence, HIF1A accumulates, enters the nucleus and drives transcription of a multitude of target genes [29-31].

In this study, we investigated the consequences of a chronic hypoxia-like response triggered in cone photoreceptors to elucidate the mechanisms of cell death in cone degenerative diseases such as AMD. To this end, we used $R 91 \mathrm{~W} ; \mathrm{Nrl}^{-/}$double-mutant mice which express only cone photoreceptors in a well-layered, functional retina [32]. To induce the hypoxia-like response, we ablated the VHL protein specifically from cones using the Cre-loxP system. We analyzed the effects of the cone-specific activation of the hypoxic response and validated the contribution of HIF1A to the resulting retinal pathology.

\section{Methods}

\section{Mice}

All experimental procedures were performed according to 'The Association for Research in Vision and Ophthalmology' statement on animal use in ophthalmic and vision research and the regulation of the veterinary authorities of Kanton Zurich, Switzerland. R91 W;Nrl ${ }^{-/}$mice were generated by crossing Rpe65 $5^{R 91 W}$ (R91W) [33] to $\mathrm{Nr}^{-/-}$ mice [34], and were described recently [32]. $B P C r e ; R 91 \mathrm{~W} ; \mathrm{Nr}^{-/} ; V h l^{f f}\left(=c o n e^{\Delta V h l}\right)$ mice were generated by breeding $\mathrm{R} 91 \mathrm{~W} ; \mathrm{Nr}^{-/}$mice to $\mathrm{Vh} \mathrm{f}^{\mathrm{f} / \mathrm{f}}$ mice [35] and mice expressing the Cre recombinase under the transcriptional control of the blue cone opsin (BP) promoter [36]. To

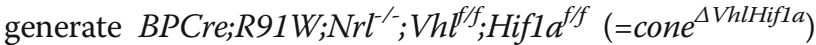
mice, $B P C r e ; R 91 \mathrm{~W} ; \mathrm{Nrl}^{-/} ; \mathrm{Vh} \boldsymbol{f}^{f / f}$ were bred to Hifla ${ }^{f / f}$ mice [37]. $\mathrm{R} 91 \mathrm{~W} ; \mathrm{Nrl}^{-/} ; \mathrm{Vh} t^{f / f}$ and $\mathrm{R} 91 \mathrm{~W} ; \mathrm{Nrl}^{-/}$; $\mathrm{Vh} \mathrm{fl}^{f f} ; \mathrm{Hifla}^{f / f}$ littermates without $\mathrm{Cre}$ recombinase served as respective control mice $(=c t r l)$. Genotyping was performed by PCR using DNA isolated from ear clips and primer pairs as described previously $[38,39]$. Presence of $B P C r e$ was tested using the following primer pair: forward (5'-GGACATGTTCAGGGATCGCCAGGCG-3') and reverse (5'GCATAACCAGTGAAACAGCATTGCTG-3'). The amplification reaction resulted in a 268 bp fragment in the presence of the transgene. To test for deletion of floxed sequences, genomic DNA was isolated from retinal tissues and tested by PCR using appropriate primer pairs as described [38, 39]. 12956 (Taconic, Ejby, Denmark) mice were used as wild-type controls. To test expression of the Cre recombinase $\mathrm{BPCre} ; \mathrm{R} 91 \mathrm{~W} ; \mathrm{Nr}^{-/}$mice were bred to a ZsGreen reporter line (Ai6 mice, Gt(ROSA)26Sor ${ }^{\text {tmb(CAG- }}$ ZsGreen1)Hze, [40]). Mice of both sexes were used for experiments and were housed at the animal facility of the University Zurich under a $14 \mathrm{~h}: 10 \mathrm{~h}$ light/dark cycle with lights on at 6 am and lights off at $8 \mathrm{pm}$. Food and water were provided ad libitum.

\section{Morphology/quantification}

To evaluate retinal morphology, eyes were enucleated and fixed in $2.5 \%$ glutaraldehyde in cacodylate buffer $(\mathrm{pH} 7.2,0.1 \mathrm{M})$, according to the previously described procedure [41]. By cutting through the optic nerve head, nasal and temporal halves of the eyecups were separated and embedded in epon plastic. Semi-thin cross sections $(0.5 \mu \mathrm{m})$ were counterstained with toluidine blue and analyzed by light microscopy (Axioplan; Zeiss, Jena, Germany). Thickness of the outer nuclear layer was measured at indicated distances from the optic nerve head using the Adobe Photoshop CS6 ruler tool (Adobe Systems, Inc., San Jose, CA, USA) on reconstructed retinal panorama images.

\section{Immunofluorescence}

After euthanasia, eyes were marked nasally, enucleated and fixed in $4 \%$ paraformaldehyde (PFA) in phosphate buffer for $1 \mathrm{~h}$ at $4^{\circ} \mathrm{C}$. Cornea and lens were removed and the dissected eyecups postfixed for $2 \mathrm{~h}$ in $4 \%$ PFA. After immersion in $30 \%$ sucrose (in PBS $0.1 \mathrm{M}$ ) the eyecups were embedded in tissue freezing medium (O.C.T., Leica Biosystems Nussloch $\mathrm{GmbH}$, Nussloch, Germany), frozen in a 2-methylbutane bath cooled by liquid nitrogen and stored at $-80^{\circ} \mathrm{C}$. Cryosections $(12 \mu \mathrm{m})$ were blocked (3\% normal goat serum (Sigma-Aldrich, St. Louis, MO, USA), 0.3\% Triton X-100 (Sigma) in PBS) and incubated with the following primary antibodies overnight at $4^{\circ} \mathrm{C}$ : Isolectin GS-IB 4 -Alexa594 from Griffonia simplicifolia (1:300, I21413; Thermo Fisher Scientific, Waltham, MA, USA), rabbit anti-allograft inflammatory factor 1 (alias 
IBA1, 1:1000, 019-19741; Wako, Neuss, Germany), rabbit anti-albumin (ALB, 1:500, RARaAlb; Nordic Immunology, Tilburg, Netherlands). Sections were washed with PBS, incubated with secondary antibodies (Cy3-labeled, Jackson ImmunoResearch Laboratories, Westgrove, PA, USA) for $1 \mathrm{~h}$ at room temperature (RT), counterstained with DAPI (4',6-Diamidine-2'-phenylindole dihydrochloride, Roche, Basel, Switzerland) and analyzed by fluorescence microscopy (Axioplan; Zeiss).

\section{Analysis of retinal vasculature in whole mounted retinas}

Eyes were isolated and incubated for 5 to 10 minutes in 2\% PFA in PBS as described recently [42]. After removal of cornea and lens, the retina was dissected and flatmounted in PBS. After postfixation in 4\% PFA for $1 \mathrm{~h}$ at RT, flat-mounts were blocked ( $3 \%$ normal goat serum, $0.3 \%$ Triton X-100 in PBS, $1 \mathrm{~h}$ ) and incubated with isolectin GS-IB ${ }_{4}$-Alexa594 (1:300, Thermo Fisher Scientific) at $4^{\circ} \mathrm{C}$ overnight. Retinas were washed in PBS, mounted on glass slides and analyzed by fluorescence microscopy (Axioplan/ApoTome; Zeiss). Blood vessels were reconstructed in three dimensions using Imaris software (Versions 7.7.2/8.3.0, Bitplane AG, Zurich, Switzerland). For better recognition and distinction of the vascular plexi, the $\mathrm{z}$-value of the $\mathrm{z}$-stacks was increased five times.

\section{RNA isolation and semi-quantitative real-time PCR}

Retinas were isolated through a slit in the cornea, frozen in liquid nitrogen and stored at $-80^{\circ} \mathrm{C}$. RNA was extracted using an RNA isolation kit (RNeasy; Qiagen, Hilden, Germany) including a DNAse treatment. $1 \mu \mathrm{g}$ of RNA, oligo (dT) and M-MLV reverse transcriptase (Promega, Fitchburg, WI, USA) were used to prepare cDNA. To analyze gene expression by real-time PCR, $10 \mathrm{ng}$ of cDNA template was amplified using a PCR polymerase ready mix (LightCycler 480 SYBR Green I Master, Roche Diagnostics, Rotkreuz, Switzerland), specific primer pairs (Table 1) and a thermocycler (LightCycler 480, Roche Diagnostics). Expression levels were normalized to $\beta$ actin $(A c t b)$ and relative expression was calculated using the comparative threshold cycle method $\left(\Delta \Delta C_{\mathrm{T}}\right)$ of the LightCycler480 software (Roche Diagnostics). At least 3 mice per strain and time point were used.

\section{Protein isolation and Western blotting}

Proteins were isolated by homogenizing the retinas in ice-cold Tris- $\mathrm{HCl}$ (100 mM, pH 7.5) using ultrasound at $4^{\circ} \mathrm{C}$. Protein concentrations were determined spectrophotometrically by using Bradford reagent (Bio-Rad, Hercules, CA, USA). SDS-PAGE and Western blotting were performed as described [41] and proteins detected by rabbit anti-HIF1A (1:2000, NB100-479, Novus Biologicals, Littleton, CO, USA) and mouse anti- $\beta$-actin (1:10'000, A5441, Sigma-Aldrich) antibodies. HRP- conjugated secondary antibodies were applied for $1 \mathrm{~h}$ at RT and signals were visualized using Western lightning chemiluminescence reagent (PerkinElmer, Waltham, MA, USA) and X-ray films.

\section{Electroretinography (ERG)}

Mice were dark-adapted overnight and pupils were dilated under dim red light with 1\% cyclogyl (Alcon Switzerland SA, Rotkreuz, Switzerland) and 5\% neosynephrin-POS (Ursapharm Schweiz GmbH, Roggwil, Switzerland) $30 \mathrm{mi}-$ nutes prior to recording. Mice were anesthetized with a subcutaneous injection of ketamine $(85 \mathrm{mg} / \mathrm{kg}$, Pfizer PFE Switzerland GmbH, Zurich, Switzerland) and xylazine (Rompun 2\%, $4 \mathrm{mg} / \mathrm{kg}$, Bayer, Leverkusen, Germany). To keep the cornea moist, a drop of mydriaticum dispersa (Omnivision AG, Neuhausen, Switzerland) was applied to each eye. Low background illumination for $5 \mathrm{~min}$ was used for light adaptation. Electroretinograms were recorded simultaneously from both eyes with an LKC UTAS Bigshot unit (LKC Technologies, Inc. Gaithersburg, MD, USA) as described [32]. Flashes of 8 different light intensities ranging from -10 to $25 \mathrm{~dB}\left(0.25-790.5694 \mathrm{~cd}^{*} \mathrm{~s} / \mathrm{m}^{2}\right)$ were applied under photopic conditions. 10 responses were averaged per light intensity. Traces from $n \geq 4$ mice were averaged for each light intensity.

\section{Fundus imaging and fluorescein angiography}

Fundus photographs were taken with a Micron IV system (Phoenix Research Labs, Pleasanton, CA, USA). The pupils were dilated and the mice were anesthetized as described above. Methocel 2\% (Omnivision) was applied to lubricate the eyes. Fluorescein images were captured 1-5 minutes after intraperitoneal injection of $20 \mu \mathrm{L}$ of $2 \%$ fluorescein solution (Akorn, Lake Forest, IL, USA).

\section{Experimental design and statistical analysis}

Two-way ANOVA with Š́dák's multiple comparison test was performed using GraphPad Prism (version 7.02, GraphPad Software, San Diego, CA, USA) for statistical analysis of gene expression levels and ERG traces. All data are shown as means $\pm \mathrm{SD}$.

\section{Results}

Cone-specific inactivation of $\mathrm{Vhl}$ increased HIF1A target gene expression and induced progressive cone degeneration

Photoreceptors in the all-cone $\mathrm{R} 91 \mathrm{~W} ; \mathrm{Nrl}^{-/-}$mouse are predominantly blue-light sensitive S-cones [32, 34]. Therefore, we used $\mathrm{BP}$-Cre transgenic mice, which express functional Cre recombinase under the transcriptional control of the blue cone opsin promoter (BP, [36]) to delete floxed sequences from cones in the all-cone mice. $\mathrm{BPCre} ; \mathrm{R} 91 \mathrm{~W} ; \mathrm{Nrl}^{-/} ; \mathrm{ZsGreen}$ reporter mice verified that $C r e$ expression was uniform over the entire retina 
Table 1 Primers used for real-time PCR

\begin{tabular}{|c|c|c|c|}
\hline Gene & Forward $\left(5^{\prime}-3^{\prime}\right)$ & Reverse $\left(5^{\prime}-3^{\prime}\right)$ & Product (bp) \\
\hline Actb & CAACGGCTCCGGCATGTGC & CTCTTGCTCTGGGCCTCG & 153 \\
\hline Adm & TCCTGGTTTCTCGGCTTCTC & ATTCTGTGGCGATGCTCTGA & 133 \\
\hline Bnip3 & CCTGTCGCAGTTGGGTTC & GAAGTGCAGTTCTACCCAGGAG & 93 \\
\hline Caspl & GGCAGGAATTCTGGAGCTTCAA & GTCAGTCCTGGAAATGTGCC & 138 \\
\hline Fgf2 & TGTGTCTATCAAGGGAGTGTGTGC & ACCAACTGGAGTATTTCCGTGACCG & 158 \\
\hline Gfap & CCACCAAACTGGCTGATGTCTAC & ТTСТCTCCAAATCCACACGAGC & 240 \\
\hline Glut1 & CAGTGTATCCTGTTGCCCTTCTG & GCCGACCCTCTTCTTTCATCTC & 151 \\
\hline Pdgfb & GCTGCTGCAATAACCGCAAT & GTGGTCCTCCAAGGTCACTG & 131 \\
\hline Pdgfrb & CTTGCCCTTCAAAGTGGTGG & CCAGGTGGAGTCGTAAGGC & 199 \\
\hline Egln1 & GCAGCATGGACGACCTGAT & CAACGTGACGGACATAGCCT & 123 \\
\hline Sema3f & CGTCGCGCACAGGATTA & GGAAAATGGCTGCATCGGTA & 166 \\
\hline Timp3 & GCCTCAAGCTAGAAGTCAACAAA & TGTACATCTTGCCTTCATACACG & 69 \\
\hline Vegf & ACTTGTGTTGGGAGGAGGATGTC & AATGGGTTTGTCGTGTTTCTGG & 171 \\
\hline$v W F$ & CCCTGGACAACTTGACAGCAG & ACAAGCAGGCAGATCTCATACC & 192 \\
\hline
\end{tabular}

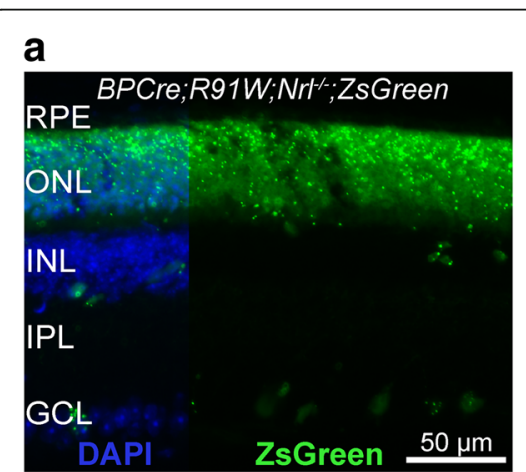

d

Adm

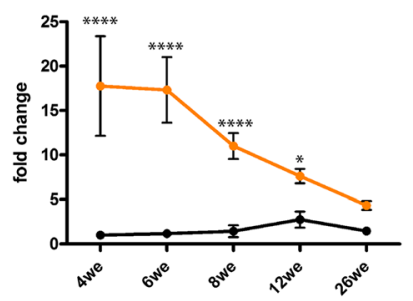

b

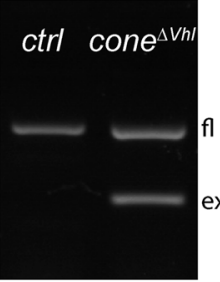

C

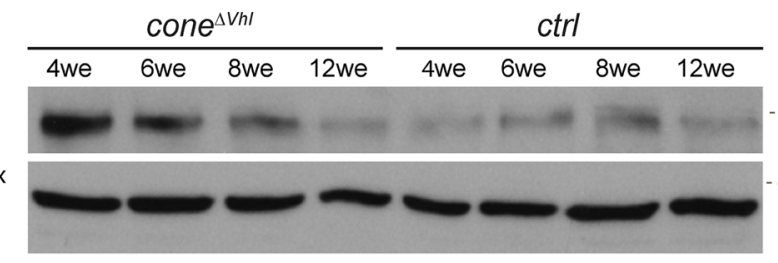

HIF1A

$-48 \mathrm{kDa}$

ACTB

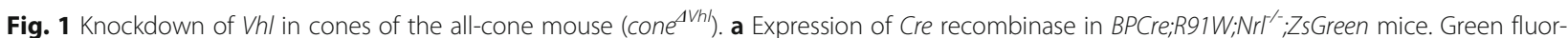
escence (ZsGreen) indicates Cre activity. RPE: retinal pigment epithelium, ONL: outer nuclear layer, INL: inner nuclear layer, IPL: inner plexiform layer, GCL: ganglion cell layer. Scale bar $50 \mu \mathrm{m}$. b PCR of genomic DNA from retinas of 4-week-old ctrl and cone ${ }^{\Delta V h l}$ mice. Floxed Vhl (fl) is detected at $460 \mathrm{bp}$ and Cre-mediated excision (ex) results in a 260 bp fragment. c Western blot analysis of HIF1A in 4, 6, 8 and 12-week-old cone ${ }^{A V h l}$ and ctrl (littermates without Cre recombinase) mice. ACTB served as loading control. $\mathbf{d}$ Relative expression of hypoxic target genes in retinas of ctrl (black) and cone ${ }^{A V h l}$ (orange) mice. Expression levels were normalized to beta-actin (Actb) and calculated relatively to 4-week-old ctrl mice, which were set to 1. Shown are means \pm SD. Two-way ANOVA with Šídák's multiple comparison test was used for statistical analysis (Adm: ${ }^{* * * *} p<0.0001$, ${ }^{*} p=0.0306$; Egln 1: ${ }^{* * *} p<0.0001$; Glut1: ${ }^{* * *} p<0.0001 ;$ Bnip3: ${ }^{* * *} p<0.0001,{ }^{* *} p=0.0043 ; n \geq 3$ per time point). Adm: Adrenomedullin, Egln 1: egl-9 family hypoxia-inducible factor 1, Glut1: Glucose transporter 1, Bnip3: BCL2/adenovirus E1B interacting protein 3. Cre-negative littermates were used as ctrl mice in all experiments unless otherwise indicated 
and restricted almost exclusively to the majority of cones in the ONL (Fig. 1a). Green fluorescence of the activated reporter protein was only occasionally detected in few cells of the inner retina. We validated $V h l$ excision in the $B P C r e ; R 91 \mathrm{~W} ; \mathrm{Nrl}^{-/} ; \mathrm{Vh} l^{f / f}\left(=\mathrm{cone} e^{\Delta V h l}\right)$ mouse line by analyzing genomic DNA isolated from retinal tissues of 4-week-old cone ${ }^{\Delta V h l}$ mice. The detection of a PCR product corresponding to the excised fragment suggested a successful Cre-mediated deletion of $\mathrm{Vhl}$ in retinas of cone $e^{\Delta V h l}$ but not of ctrl mice (=R91 W;Nrt ${ }^{-1} ; V h t^{f / f}$, Fig. 1b). Genomic deletion of $V h l$ led to the accumulation of HIF1A protein (Fig. 1c) and to increased transcript levels of known hypoxic target genes such as adrenomedullin (Adm), egl-9 family hypoxia-inducible factor $1(E g \ln 1$, also known as Phd2), glucose transporter 1 (Glut1) and BCL2/ adenovirus E1B 19-kDa interacting protein 3 (Bnip3) in normoxic cone $e^{\Delta V h l}$ mice (Fig. 1d). This suggested that cells, presumably cones, activated a hypoxia-like response in retinas of $c o n e^{\Delta V h l}$ mice.

We observed an age-dependent decline in HIF1A protein levels and hypoxia target gene expression in cone ${ }^{\Delta V h l}$ mice (Fig. 1c, d). This prompted us to analyze retinal function and morphology. B-wave amplitudes and photopic ERGs were not significantly different between cone ${ }^{\Delta V h l}$ mice and ctrl mice at 6 weeks of age (Fig. 2a). However, the amplitudes were strongly reduced in 12 -week-old cone $e^{\Delta V h l}$ mice as compared to age-matched ctrl mice (Fig. 2b). This indicated an age-dependent loss of function potentially due to retinal degeneration. Indeed, we observed severe, progressive thinning of the outer nuclear layer (ONL) in cone $e^{\Delta V h l}$ mice with most cones lost at 26 weeks of age (Fig. 3a, b). Additionally, partial loss of
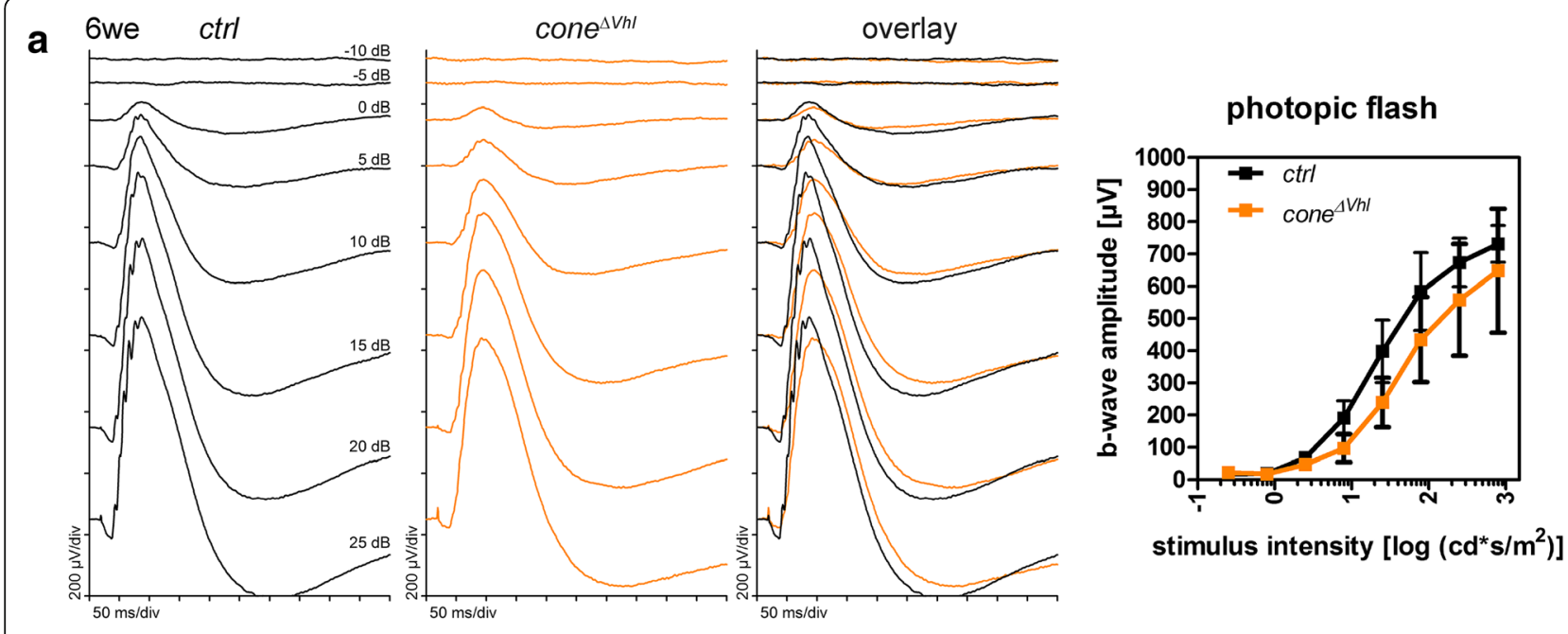

b
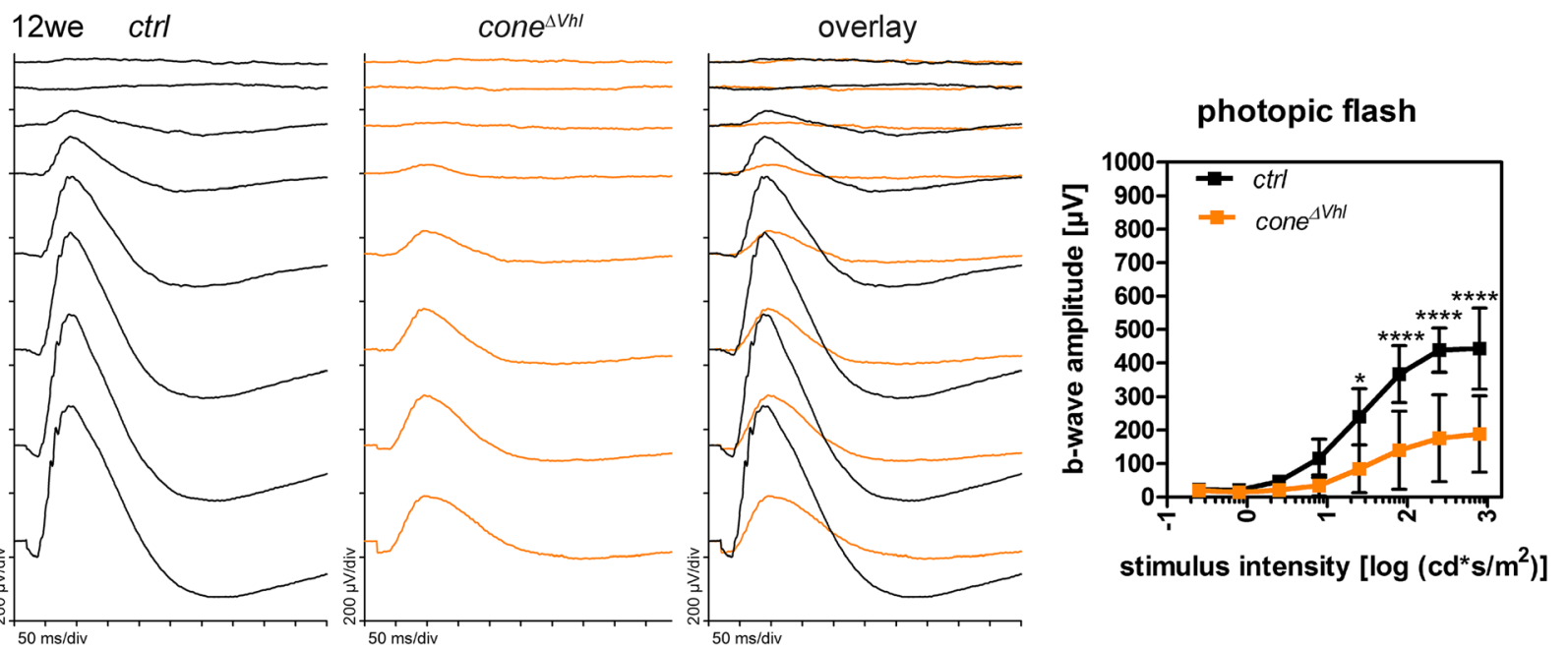

Fig. 2 Reduced retinal function in aged cone $e^{A \mathrm{Vh}}$ mice. a Averaged traces of single-flash photopic ERGs and b-wave amplitudes showed no significant differences in cone $e^{A V h l}$ mice (orange) compared to ctrl mice (black) at 6 weeks of age. $\mathbf{b}$ At 12 weeks of age, photopic b-wave amplitudes were strongly reduced in cone $e^{\Delta V h l}$ mice (orange) as compared to ctrl mice (black). b-wave amplitudes are shown as means \pm SD. Two-way ANOVA with Šídák's multiple comparison test was used for statistical analysis (6we ctrl and cone ${ }^{\Delta V h l} n=5,12 \mathrm{we} c \mathrm{trl} n=6$ and cone ${ }^{\Delta V h l} n=4,{ }^{*} p=0.0115,{ }^{* * * *} p<0.0001$ ) 


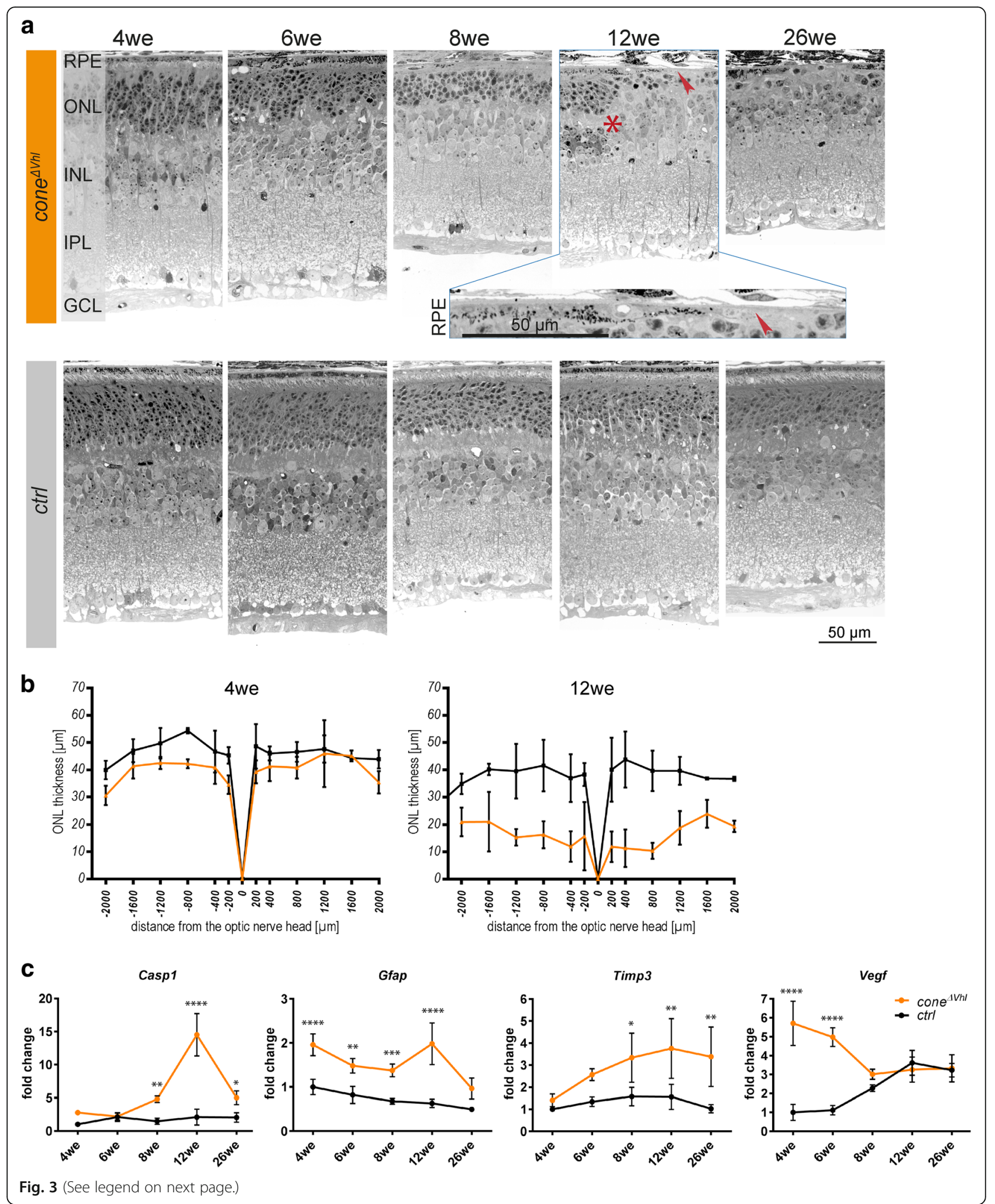


(See figure on previous page.)

Fig. 3 Progressive cone degeneration in cone $e^{\Delta V h l}$ mice. a Inactivation of $V h /$ in cones led to progressive retinal degeneration (upper panels) as compared to $\mathrm{ctrl}$ mice (lower panels). Cone ${ }^{\Lambda \mathrm{Vhl}}$ mice displayed disturbed layering with reorganization of the INL (asterisk, 12we cone ${ }^{\Lambda \mathrm{Vh}}$ ), severe loss of the ONL and partial loss of the RPE (arrowhead, 12we cone ${ }^{\Delta V h l}$, inset) at 12 and 26 weeks of age. Abbreviations as in Fig. 1 . Scale bar 50 $\mu \mathrm{m}$. $\mathbf{b}$ Line chart of ONL thickness in cone ${ }^{A V h l}$ mice (orange) as compared to ctrl mice (black) at 4 and 12 weeks of age. $n \geq 3$. c Relative expression levels of genes involved in stress signaling and degeneration. Expression levels were normalized to Actb and calculated relatively to 4-week-old ctrl mice, which were set to 1. Shown are means \pm SD. Two-way ANOVA with Šídák's multiple comparison test was used for statistical analysis (Casp 1: ${ }^{* *} p=0.0026,{ }^{* * * *} p<0.0001,{ }^{*} p=0.0244$, Gfap: ${ }^{* * * *} p<0.0001,{ }^{* *} p=0.0035,{ }^{* * *} p=0.0004,{ }^{* * * *} p<0.0001$, Timp3: ${ }^{*} p=0.0235,{ }^{* *} p=0.0036,{ }^{* *} p=0.0035$, Vegf: ${ }^{* * *} p<0.0001, n \geq 3$ per time point). Casp1: caspase 1, Gfap: glial fibrillary acidic protein, Timp3: tissue inhibitor of metalloproteinase 3, Vegf: vascular endothelial growth factor

the retinal pigment epithelium (RPE) and strong perturbations in the inner nuclear layer (INL) were detected in older cone ${ }^{\Delta V h l}$ mice (Fig. 3a, 12we cone ${ }^{\Delta V h l}$ ). In contrast, the ctrl mice showed only a slow agerelated ONL thinning, as reported for the parental $\mathrm{R} 91 \mathrm{~W} ; \mathrm{Nrl}^{-/-}$mouse line before [32].

To gain insight into cellular mechanisms leading to cone degeneration, we analyzed expression of specific genes during aging in cone $e^{\Delta V h l}$ and ctrl mice (Fig. 3c). Caspase 1 (Casp1), a gene involved in retinal degeneration, was upregulated in $c o n e^{\Delta V h l}$ mice at 8 weeks and peaked at 12 weeks of age. Expression of the stress signaling gene glial fibrillary acidic protein (Gfap) was upregulated in $c o n e^{\Delta V h l}$ mice already at 4 weeks and remained elevated throughout the observation period. Interestingly, we observed increased expression of tissue inhibitor of metalloproteinase 3 (Timp3) during the aging process, a gene associated with age-related macular degeneration [43, 44]. Similarly, expression of vascular endothelial growth factor $($ Vegf), a hypoxic response gene that is involved in neovascularization in wet AMD, was strongly increased in $c o n e^{\Delta V h l}$ mice at 4 and 6 weeks of age.

\section{Subretinal neovascularization and vascular leakage in cone $^{\Delta V h l}$ mice}

Increased transcription of Timp3 is potentially associated with a higher risk to develop neovascular AMD [43] and hypoxia-regulated genes such as Vegf contribute to retinal and choroidal neovascularization (reviewed in [45]). Therefore, we analyzed the vascular network of cone $e^{\Delta V h l}$ mice. All three vascular plexi were detected at 4 weeks of age (Fig. 4a, b, c). However, we observed vessels extending from the deep plexus into the normally avascular ONL in central retinas of $c o n e^{\Delta V h l}$ mice (Fig. 4a, arrowheads). Vessels reached the RPE but did not cross Bruch's membrane (Fig. 4d, e), as we never observed retinal-choroidal anastomoses. This suggests that abnormal vessels originated from the retinal vasculature and not from the choroid. Interestingly, abnormal vessel growth was characteristic for the central but not for the peripheral retina (Fig. 4b). To evaluate the integrity of retinal vessels we performed fluorescein angiography. Signs of leakage were observed in cone $e^{\Delta V h l}$ mice (Fig. 4f, g). To confirm these findings we stained retinal crosssections for albumin (ALB), a marker for blood extravasation. Detailed analysis revealed strong ALB immunoreactivity in the ONL, RPE and inner plexiform layer (IPL) in $c o n e^{\Delta V h l}$ mice, as opposed to the signal detected in ctrl mice that was confined to retinal vessels. The choroid with its extensive vasculature was also strongly positive for ALB in both types of mice (Fig. 4h, i). Microglia/ macrophages detected by IBA1 staining were found within the photoreceptor and subretinal layer in $\operatorname{con} e^{\Delta V h l}$ but not ctrl mice (Fig. 4j, k).

\section{Early vascular defects in cone $e^{\Delta V h l}$ mice}

S-opsin expression starts shortly before birth in mice [46, 47] and we observed Cre-activity in $\mathrm{BPCre} ; \mathrm{R} 91 \mathrm{~W} ; \mathrm{Nrl}^{-1} ; \mathrm{Zs}$ Green reporter mice as early as at postnatal day (PND) 1 (data not shown). The primary plexus in mice develops along a central-to-peripheral gradient and reaches the periphery around PND8-10 [48]. Vessels sprout from the primary plexus into the retina and turn laterally when they reach the outer and inner boundaries of the INL to first form the deep plexus and subsequently the intermediate plexus [48]. To determine the onset of neovascularization in cone $e^{\Delta V h l}$ mice we stained retinal flat mounts with isolectin at PND7 and PND11. Using 3D-reconstruction of blood vessels, no difference in early vessel formation was detected between cone $e^{\Delta V h l}$ and ctrl mice at PND7 (Fig. 5a). However, at PND11, before formation of the intermediate plexus, vessels growing from the deep plexus into the ONL were observed in cone $e^{\Delta V h l}$ mice (Fig. 5b).

Formation of the deep plexus is preceded by Vegf expression in the INL [49]. We analyzed gene expression levels in cone $e^{\Delta V h l}$, ctrl and $129 S 6$ ( $w t$, rod-dominant retina) mice to test for different regulation of genes involved in angiogenesis and vessel guidance during and after the process of vessel formation (PND7, 14 and 28, Fig. 5c). Vegf mRNA was not elevated at PND7, slightly increased by 1.3-fold at PND14 and significantly increased at PND28 (2-fold) in cone $e^{\Delta V h l}$ mice compared to controls. Fibroblast growth factor 2 ( Fgf2), a potent angiogenic factor that has been shown to be involved in retinal stress [50-52], was upregulated at PND28, at a time when developmental vascularization is completed. 


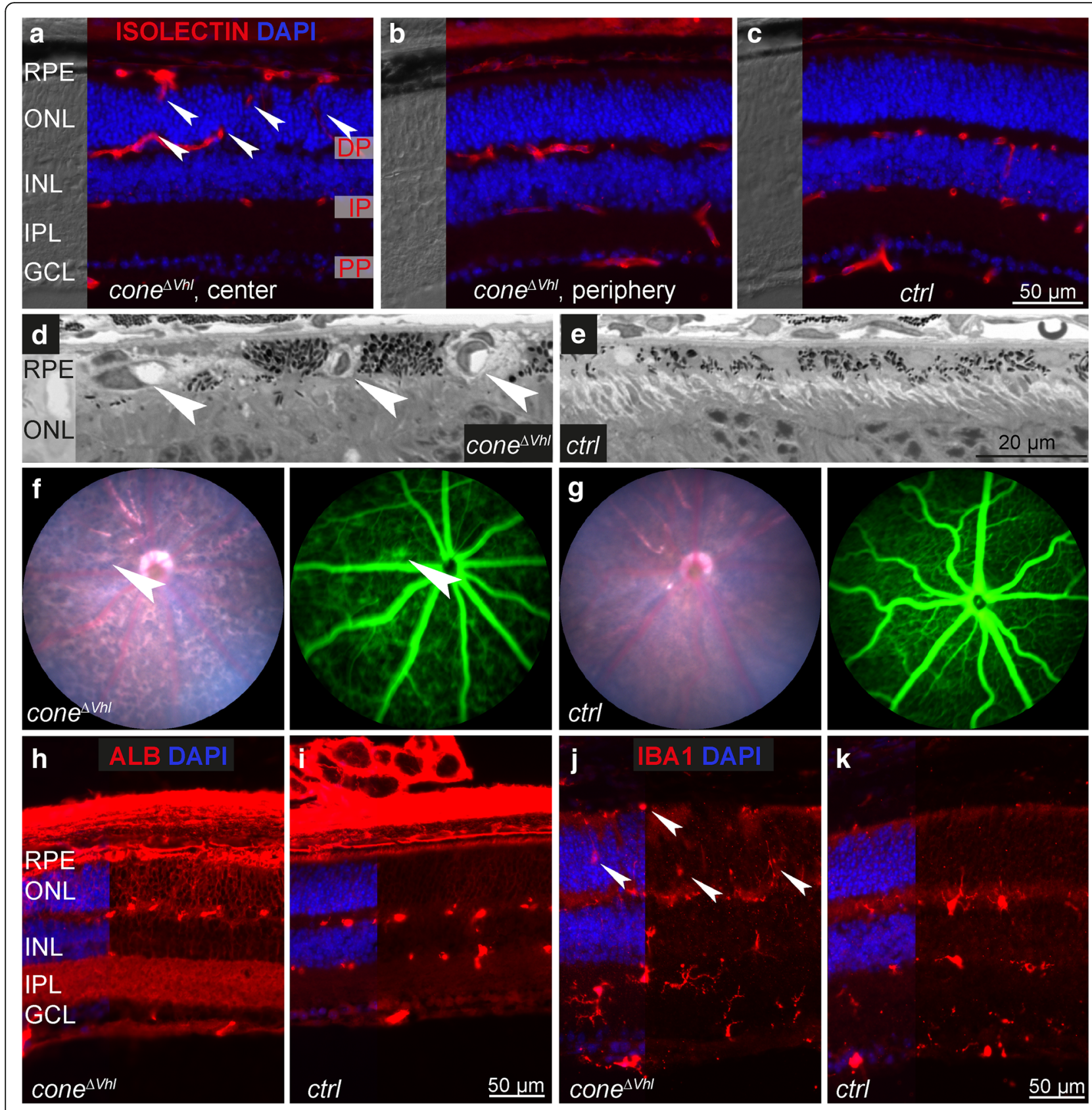

Fig. 4 Subretinal neovascularization in cone ${ }^{\Delta V h l}$ mice. a-c Immunostaining of cross-sections of the central (a) and peripheral (b) retina of 4-week-old cone $e^{\Delta V h l}$ and age-matched ctrl mice (c, central retina) with isolectin. Arrowheads indicate vessels extending from the deep plexus into the ONL in central retinas of cone $e^{\Delta V h l}$ mice. DP: deep plexus, IP: intermediate plexus, PP: primary plexus. Scale bar $50 \mu m$. d, e Light microscopy of 4-week-old cone ${ }^{\Delta V h l}$ and ctrl mice. Neovessels (arrowheads) reached the RPE, but did not cross Bruch's membrane. Scale bar $20 \mu \mathrm{m}$. f, g Fundus imaging and fluorescein angiography of cone ${ }^{\Delta V h l}$ mice and ctrl mice at 4 weeks of age. Signs of leakage (arrowhead) were detected in cone $e^{\Delta V h l}$ mice. $\mathbf{h}-\mathbf{k}$ Retinal cross-sections of $c t r l \mathbf{h}, \mathbf{j}$ and cone $e^{\Delta V h l}$ mice $(\mathbf{i}, \mathbf{k})$ were stained with antibodies against ALB $(\mathbf{h}, \mathbf{i})$ and IBA1 $(\mathbf{j}, \mathbf{k})$ at 4 weeks of age. Microglia/macrophages were found within the photoreceptor layer and RPE in cone ${ }^{\Delta V h l}$ mice (arrowheads). Scale bar $50 \mu \mathrm{m}$. Abbreviations as in Fig. 1

Recently, protective effects of semaphorin 3F (Sema3f) against subretinal neovascularization have been demonstrated [53]. We thus analyzed Sema3f gene expression levels to test for potential differential expression of this anti-angiogenic factor in cone $e^{\Delta V h l}$ mice. However, expression of Sema3f in all-cone mice did not differ between $\mathrm{ctrl}$ and cone ${ }^{\Delta V h l}$ mice (Fig. 5c). On the other hand, a pro-angiogenic factor, platelet derived growth factor, B polypeptide $(P d g f b)$, was upregulated in con$e^{\Delta V h l}$ compared to $c t r l$ mice at PND28. Pdgfb expression 


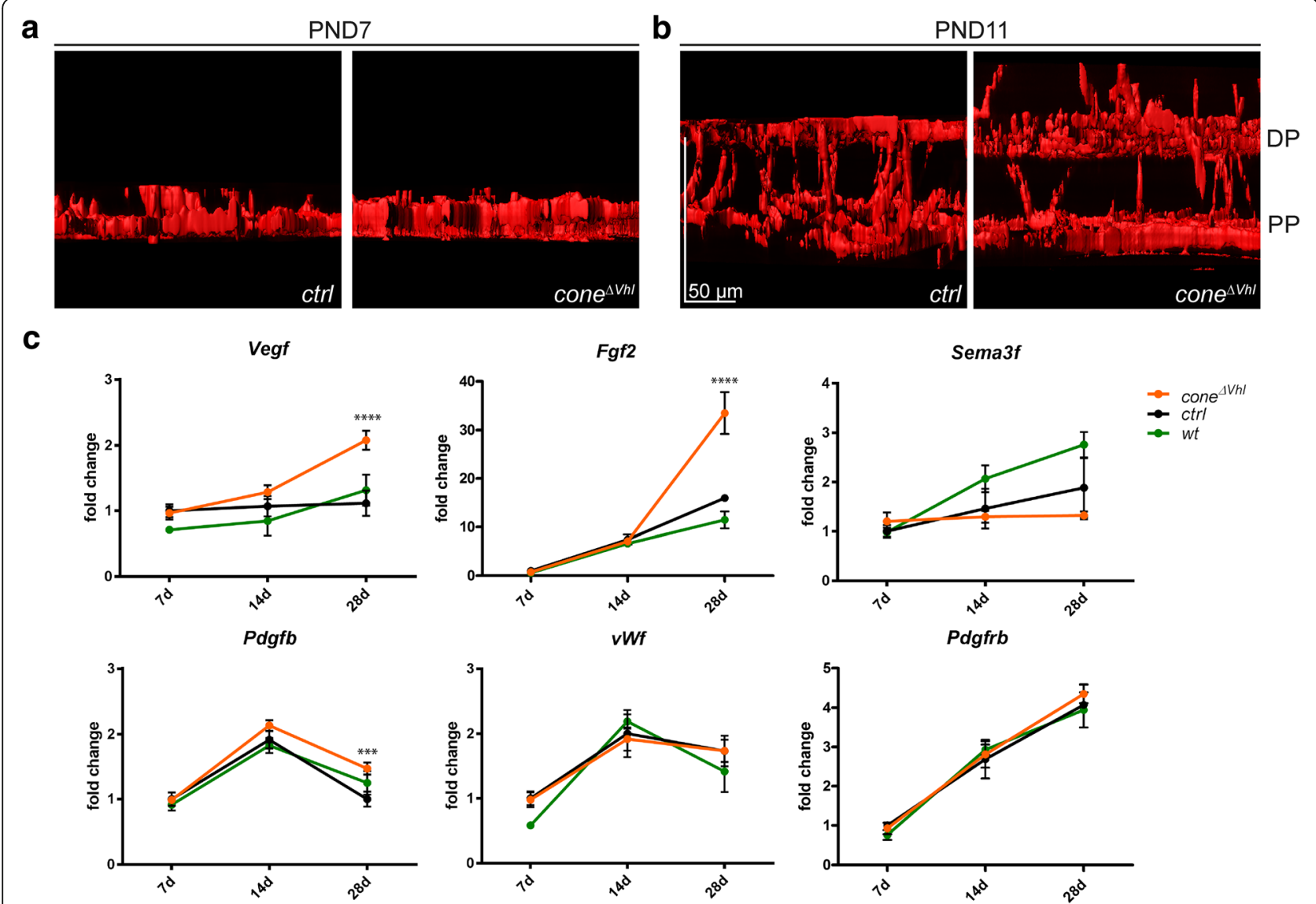

Fig. 5 Pathological vessel growth starts around PND11 in cone $e^{\Delta V h l}$ mice. $\mathbf{a}, \mathbf{b}$ 3D-reconstruction of blood vessels stained with isolectin on retinal flat mounts of ctrl (left) and cone $e^{\Delta V h l}$ (right) mice at PND7 (a) and PND 11 (b). At PND11, vessels extended from the deep plexus towards the ONL. The intermediate plexus has not yet been formed in both $\mathrm{ctrl}$ and cone ${ }^{\Delta V h l}$ mice. For better recognition and distinction the $z$-value of the z-stacks was increased five times. DP: deep plexus, PP: primary plexus. Scale bar $50 \mu m$. c Relative expression levels of angiogenic genes in retinas of cone ${ }^{\Delta V h l}$ (orange), ctrl (black) and wt (green) mice at indicated time points. Expression levels were normalized to Actb and compared to ctrl mice at PND7, which were set to 1. Shown are means \pm SD. Two-way ANOVA with Šídák's multiple comparison test was used for statistical analysis comparing ctrl with cone ${ }^{\Delta V h l}$ mice (Vegf: ${ }^{* * *} p<0.0001, F g f 2:{ }^{* * *} p<0.0001, P d g f b$ : ${ }^{* * *} p=0.0009, n=3$ per time point). Vegf: vascular endothelial growth factor, Fgf2: fibroblast growth factor 2, Sema3f: semaphorin 3F, Pdgfb: platelet derived growth factor, B polypeptide, vWf: von Willebrand factor, Pdgfrb: platelet derived growth factor receptor, beta polypeptide

by endothelial cells is essential for pericyte recruitment and is increased under hypoxia [54-57]. Surprisingly, expression levels of von Willebrand factor $(\nu W f)$, a marker for endothelial cells, as well as of Pdgfb receptor (Pdgfrb), which is expressed by pericytes/mural cells [58-61], were not increased in $c o n e^{\Delta V h l}$ mice as compared to controls. The reason for this unexpected pattern of expression is not clear and requires further investigation.

HIF1 is responsible for pathological vessel growth and progressive cone degeneration in cone ${ }^{\Delta V h l}$ mice

We hypothesized that stabilized HIF1A, and not other Vhl targets, might promote retinal degeneration and neovascularization in $c o n e^{\Delta V h l}$ mice. Therefore, we additionally deleted Hifla in cone photoreceptors $\left(\right.$ BPCre;R91 W;Nrl ${ }^{--} ; V_{h} f^{f f f} ; H i f 1 a^{f / f}=$ cone $\left.^{\Delta \text { VhlHifla }}\right) . \quad$ After we confirmed the presence of deletion alleles for both Hifla and Vhl in genomic DNA of cone $e^{\Delta \text { VhlHifla }}$ retinas (not shown) we determined retinal function. At 12 weeks of age, photopic ERG traces and b-wave amplitudes were similar in cone $e^{\Delta V h l H i f l a}$ and $\operatorname{ctrl}\left(R 91 \mathrm{~W} ; \mathrm{Nr}^{-1}\right.$; Vht $\boldsymbol{f}^{f / f_{i}}$ Hifla ${ }^{f / f}$ ) mice (Fig. 6a, b) indicating no functional loss upon combined Hifla and $V h l$ inactivation. Similarly, retinal morphology (Fig. 6c) and ONL thickness (Fig. 6d) of cone $e^{\Delta \text { VhlHifla }}$ mice was comparable to ctrl mice, whereas the thickness of the ONL in cone ${ }^{\Delta V h l}$ mice was prominently reduced (same data as in Fig. 3b) at 12 weeks of age.

Combined deletion of Hifla and $V h l$ also prevented pathological neovascularization into the ONL but had no effect on the developmental formation of the three vascular plexi (Fig. 6e). No induction of the expression 


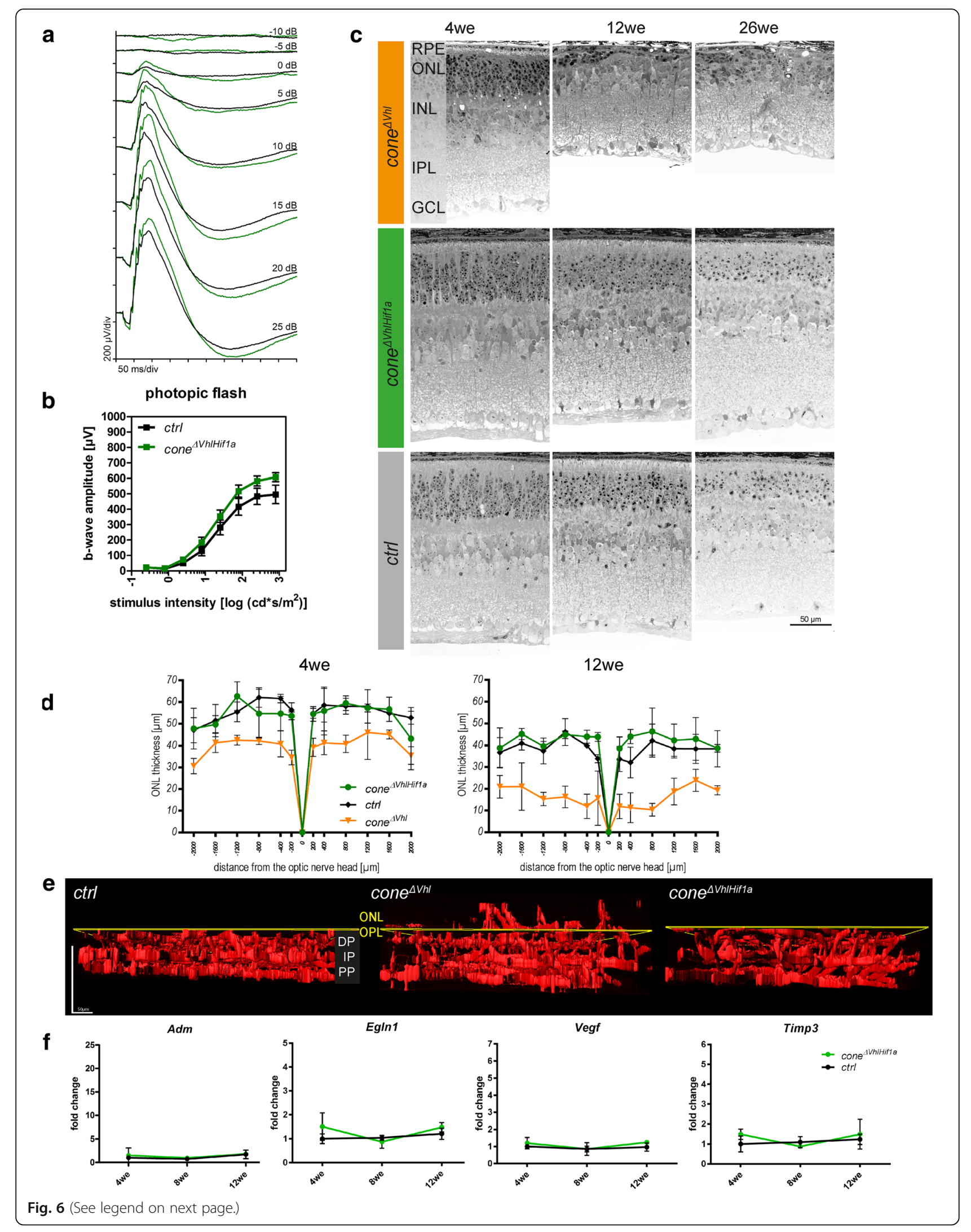




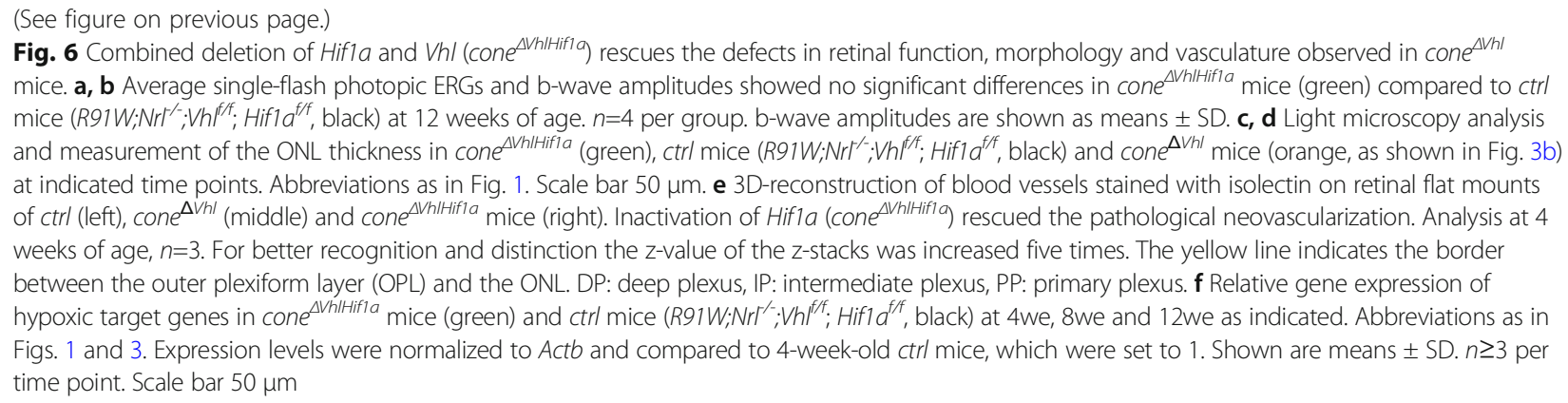

of hypoxic target genes such as Adm, Egln1, Vegf and Timp3 was detected in cone $e^{\Delta \text { VhlHifla }}$ mice, confirming that HIF1 was the responsible HIF isoform for regulating their expression in cones (Fig. 6f). Altogether, these data demonstrate that combined deletion of Hifla and Vhl (cone $e^{\Delta V h l H i f l a}$ mice) rescues the retinal phenotype observed in cone $e^{\Delta V h l}$ mice and identify HIF1 as the causative factor for retinal degeneration and pathological vessel growth in cone $e^{\Delta V h l}$ mice.

\section{Discussion}

Previously, it has been demonstrated that the knockdown of $V h l$ in rod cells causes HIF1A stabilization under normoxic conditions [39]. Here, we particularly investigated the effects of a chronic hypoxia-like response in cone photoreceptors. We show that ablation of $V h l$ in cones resulted in a chronic hypoxia-like situation with accumulation of HIF1A and induction of HIF1A target genes. This led to pathological vessel growth into the photoreceptor layer, reduced retinal function and severe, progressive cone degeneration. These consequences resemble some of the features of AMD pathology, particularly of a subset of neovascular AMD known as RAP. In human patients, HIF1A and HIF2A were detected in macrophages and endothelial cells of neovascular membranes associated with AMD [62]. Additionally, the correlation of drusen density and decreased choroidal blood flow [26] as well as choroidal ischemia in AMD patients [23-25] suggest reduced oxygen transport from the choroid to the inner retina [63]. Therefore, tissue hypoxia and HIFs might play an important role in disease development and/ or progression.

Expression of numerous genes involved in metabolism, stress, cell survival and angiogenesis was increased in cone $e^{\Delta V h l}$ mice (Fig. 1d, 3c, 5c), as was Timp3 (Fig. 3c). TIMP3 is an important regulator of extracellular matrix (ECM) remodeling through inhibition of matrix metalloproteases and has been suggested to be a senescencerelated protein [64] that is potentially regulated by HIF2 in rods [38]. Importantly, TIMP3 inhibits angiogenesis by interacting with VEGF [65] and is relevant for Bruch's membrane integrity $[64,66]$. Furthermore, mutations in
Timp3 have been associated with Sorsby's fundus dystrophy, an autosomal dominant maculopathy with submacular choroidal neovascularization $[67,68]$. We can only speculate about the reasons for elevated Timp3 during the aging process in cone $e^{\Delta V h l}$ mice but it seems plausible that retinas of $c o n e^{\Delta V h l}$ mice require extensive ECM remodeling due to progressive cone degeneration (Fig. 3).

We detected early and prominent vascular defects with abnormal vessel growth into the ONL, subretinal space and RPE layer in cone $e^{\Delta V h l}$ mice. Increased VEGF levels in transgenic mice expressing Vegf under the transcriptional control of the rhodopsin promoter (rho/VEGF mice) were shown to cause subretinal neovascularization [69-71]. In our model, Vegf was not upregulated at PND14, at a time when vessels had already started growing into the ONL (Fig. 5). However, transient Vegf expression in the INL regulates the formation of the deep plexus during development [49], i.e. already minor changes in the local Vegf concentration gradient, which are not detectable by RT-PCR, may misguide retinal vessels in $c o n e^{\Delta V h l}$ mice. To date, it remains unclear which pro-angiogenic factor(s) are responsible for the observed neovascularization. Nonetheless, our findings demonstrate that this is a Hifla-mediated mechanism, as additional deletion of Hif1a fully rescued the vascular defects (Fig. 6).

Interestingly, cone-specific deletion of Hifla did not affect formation of the three vascular plexi (Fig. 6e), while it has been shown that knockdown of Hif1a in most cells of the retinal periphery prevented formation of the intermediate plexus [42]. Thus, our results suggest that Hifla expression in cones, as opposed to other cells presumably in the INL, is not essential for the development of the intermediate plexus.

Our data do not define whether cone degeneration in cone $e^{\Delta V h l}$ mice is due to the effects of the chronic intrinsic activation of the hypoxic response or to early development of vascular defects. Another mouse model shows, however, that a chronic hypoxia-like response in rods leads to slow photoreceptor degeneration in the absence of reported vascular defects $\left(\operatorname{rod}^{\Delta V h l}\right.$ mice [39]). 
This suggests that the long-term activation of HIF1 may reduce cell survival by an intrinsic mechanism. During hypoxia, HIF1 regulates mitochondrial respiration and thus metabolic adaptation towards glycolysis [72] leading to reduced energy (ATP) levels and potentially starvation. It has been shown that starvation of cones may lead to cone cell death [73]. Furthermore, it has been suggested that cones might be more sensitive to reduced oxygen and nutrient levels compared to rods, for reasons not fully understood $[74,75]$. This could possibly explain the progressive degeneration and the accelerated phenotype in cone $e^{\Delta V h l}$ compared to $\operatorname{rod}^{\Delta V h l}$ mice.

It might also be possible, however, that photoreceptor degeneration is secondary to the early pathological vascular defects. Inactivation of $\mathrm{Vhl}$ in the retinal periphery during development leads to vessel growth into the ONL and severe retinal degeneration [52, 76]. Whereas the retinal periphery was strongly degenerated at 10 weeks of age, photoreceptor loss in the normal vascularized central retina was less pronounced [52]. We observed microglia activation and impaired function of the bloodretina-barrier in cone $e^{\Delta V h l}$ mice, as shown by IBA1 and ALB staining, respectively (Fig. 4h-k). It seems likely that retinal hemorrhages exacerbate cone photoreceptor degeneration in our model, as suggested for other models [77, 78]. Photoreceptor degeneration was also observed in very low density lipoprotein receptor knockout mice (Vldlr ${ }^{-1}$; [79]) where early retinal neovascularization causes vessels to extend from the deep plexus into the subretinal space $[80,81]$. Interestingly, it has been suggested that the $\mathrm{Vldlr}^{-1-}$ phenotype is linked to HIF1A. Joyal and colleagues proposed that starved $\mathrm{Vldlr}^{-1-}$ photoreceptors have reduced amounts of the Krebs cycle metabolite $\alpha$-ketoglutarate, which decreases PHD activity and thus promotes stabilization of HIF1A. Consequently, Vegf is secreted, leading to RAP-like neovascularization [82]. We hypothesize that the combination of early vascular defects and the activation of a chronic hypoxia-like response, which affects expression of genes involved in cellular metabolism and retinal stress, leads to the progressive cone degeneration observed in cone $e^{\Delta V h l}$ mice.

Our findings identify HIF1 in cones as the factor causing cone degeneration, pathological neovascularization and loss of function. Similarly, chronic activation of the hypoxic response in rods resulted in an HIF1 - and age-dependent retinal degeneration (Barben et al., submitted). Whereas this provides strong evidence that activation of HIF1 in rod and cone photoreceptors leads to retinal degeneration, the activation of HIF2 but not of HIF1 is responsible for metabolic stress in RPE upon RPE-specific $V h l$ inactivation [75]. Thus, our data and data published by others suggest cell type-specific roles for HIF1A and HIF2A in retinal pathology.

\section{Conclusions}

Our data demonstrate that a chronic hypoxic response in cone photoreceptors induces HIF1A-mediated pathological vessel growth and cone degeneration. Evidence shows that HIF1A can be safely inactivated in cones (see above), rods ([38], Barben et al., submitted) and RPE [75] suggesting that targeting HIF transcription factors in photoreceptors and RPE may provide a potential therapeutic approach to rescue hypoxia-mediated retinal degeneration in patients and an alternative to anti-VEGF agents.

\section{Abbreviations \\ Adm: Adrenomedullin; ALB: Albumin; AMD: Age-related macular degeneration; Bnip3: BCL2/adenovirus E1B 19-kDa interacting protein 3; Casp1: Caspase 1; CNV: Choroidal neovascularization; DAPI: 4',6-Diamidine-2'- phenylindole dihydrochloride; ECM: Extracellular matrix; Egln1: Egl-9 family hypoxia-inducible factor 1 (known as Phd2); ERG: Electroretinography; Fgf2: Fibroblast growth factor 2; Gfap: Glial fibrillary acidic protein; Glut1: Glucose transporter 1; HIF1A: Hypoxia-inducible factor 1A; IBA1: Alias, allograft inflammatory factor 1 ; INL: Inner nuclear layer; IPL: Inner plexiform layer; ONL: Outer nuclear layer; Pdgfb: Platelet derived growth factor, B polypeptide; Pdgfrb: Pdgfb receptor; PFA: Paraformaldehyde; PHD: Prolyl hydroxylase domain; PND: Postnatal day; RAP: Retinal angiomatous proliferation; RPE: Retinal pigment epithelium; RT: Room temperature; Sema3f: Semaphorin 3F; Timp3: Tissue inhibitor of metalloproteinase 3; VEGF: Vascular endothelial growth factor; VHL: Von Hippel Lindau protein; VIdlr: Very low density lipoprotein receptor; $v W f$ : Von Willebrand factor}

\section{Acknowledgements}

The authors thank Andrea Gubler, Cornelia Imsand and Christel Beck for their excellent technical support.

\section{Funding}

Supported by the Swiss National Science Foundation (SNF \#31003A_149311 and 31003A_173008).

\section{Availability of data and materials}

All data generated or analyzed during this study are included in this published article or available from the corresponding author on reasonable request.

\section{Authors' contributions}

MB, MS, CG designed research; MB, MS, CS performed research; MB, MS, CG analyzed data, MB, MS, CG wrote the paper. All authors read and approved the final manuscript.

\section{Ethics approval and consent to participate}

All experimental procedures were performed according to The Association for Research in Vision and Ophthalmology' statement on animal use in ophthalmic and vision research and the regulation of the veterinary authorities of Kanton Zurich, Switzerland. Animal protocols were approved by the veterinary authorities of Kanton Zurich, Switzerland.

Consent for publication

Not applicable

\section{Competing interests}

The authors declare that they have no competing interests.

\section{Publisher's Note}

Springer Nature remains neutral with regard to jurisdictional claims in published maps and institutional affiliations.

\section{Author details}

'Laboratory for Retinal Cell Biology, Department of Ophthalmology, University Hospital Zurich, University of Zurich, Zurich, Switzerland.

${ }^{2}$ Neuroscience Center Zurich (ZNZ), University of Zurich, Zurich, Switzerland. 
${ }^{3}$ Zurich Center for Integrative Human Physiology (ZIHP), University of Zurich, Zurich, Switzerland.

Received: 13 September 2017 Accepted: 22 February 2018 Published online: 07 March 2018

\section{References}

1. Klein R, Klein BE, Cruickshanks KJ. The prevalence of age-related maculopathy by geographic region and ethnicity. Prog Retin Eye Res. 1999; 18(3):371-89.

2. Buch $H$, Vinding $T$, La Cour M, Appleyard $M$, Jensen GB, Nielsen NV. Prevalence and causes of visual impairment and blindness among 9980 Scandinavian adults: the Copenhagen City Eye Study. Ophthalmology. 2004; 111(1):53-61

3. Wong WL, Su X, Li X, Cheung CM, Klein R, Cheng CY, Wong TY. Global prevalence of age-related macular degeneration and disease burden projection for 2020 and 2040: a systematic review and meta-analysis. Lancet Glob Health. 2014:2(2):e106-16.

4. Green WR. Histopathology of age-related macular degeneration. Mol Vis. 1999:5:27.

5. Swaroop A, Chew EY, Rickman CB, Abecasis GR. Unraveling a multifactorial late-onset disease: from genetic susceptibility to disease mechanisms for age-related macular degeneration. Annu Rev Genomics Hum Genet. 2009; 10:19-43.

6. Spaide RF. Clinical Manifestations of Choroidal Neovascularization in AMD In: Holz FG, Pauleikhoff D, Spaide RF, Bird AC, editors. Age-related Macular Degeneration. Berlin: Springer Berlin Heidelberg; 2013. p. 111-9.

7. Rosenfeld PJ, Brown DM, Heier JS, Boyer DS, Kaiser PK, Chung CY, Kim RY, Group MS. Ranibizumab for neovascular age-related macular degeneration. N Engl J Med. 2006;355(14):1419-31.

8. Maguire MG, Martin DF, Ying GS, Jaffe GJ, Daniel E, Grunwald JE, Toth CA Ferris FL 3rd, Fine SL. Five-Year Outcomes with Anti-Vascular Endothelial Growth Factor Treatment of Neovascular Age-Related Macular Degeneration: The Comparison of Age-Related Macular Degeneration Treatments Trials. Ophthalmology. 2016;123(8):1751-61.

9. Gragoudas ES, Adamis AP, Cunningham ET, Jr., Feinsod M, Guyer DR, Group VISIONCT. Pegaptanib for neovascular age-related macular degeneration. N Engl J Med. 2004;351(27):2805-2816.

10. Bressler NM, Bressler SB, Fine SL. Age-related macular degeneration. Surv Ophthalmol. 1988;32(6):375-413.

11. Yannuzzi LA, Negrao S, lida T, Carvalho C, Rodriguez-Coleman H, Slakter J, Freund KB, Sorenson J, Orlock D, Borodoker N. Retinal angiomatous proliferation in age-related macular degeneration. Retina. 2001;21(5):416-34.

12. Hartnett ME, Weiter JJ, Staurenghi G, Elsner AE. Deep retinal vascular anomalous complexes in advanced age-related macular degeneration. Ophthalmology. 1996;103(12):2042-53

13. Yannuzzi LA, Freund KB, Takahashi BS. Review of retinal angiomatous proliferation or type 3 neovascularization. Retina. 2008;28(3):375-84.

14. Fritsche LG, Igl W, Bailey JN, Grassmann F, Sengupta S, Bragg-Gresham JL, Burdon KP, Hebbring SJ, Wen C, Gorski M, et al. A large genome-wide association study of age-related macular degeneration highlights contributions of rare and common variants. Nat Genet. 2016:48(2):134-43.

15. Chakravarthy U, Wong TY, Fletcher A, Piault E, Evans C, Zlateva G, Buggage R, Pleil A, Mitchell P. Clinical risk factors for age-related macular degeneration: a systematic review and meta-analysis. BMC Ophthalmol. 2010;10:31.

16. Remsch H, Spraul CW, Lang GK, Lang GE. Changes of retinal capillary blood flow in age-related maculopathy. Graefes Arch Clin Exp Ophthalmol. 2000; 238(12):960-4

17. Arjamaa O, Nikinmaa M, Salminen A, Kaarniranta K. Regulatory role of HIF-1 $a$ in the pathogenesis of age-related macular. Ageing Research Reviews. 2009:8:349-58.

18. Boltz A, Luksch A, Wimpissinger B, Maar N, Weigert G, Frantal S, Brannath W, Garhofer G, Ergun E, Stur M, Schmetterer L. Choroidal blood flow and progression of age-related macular degeneration in the fellow eye in patients with unilateral choroidal neovascularization. Invest Ophthalmol Vis Sci. 2010;51(8):4220-5.

19. Stefansson E, Geirsdottir A, Sigurdsson H. Metabolic physiology in age related macular degeneration. Prog Retin Eye Res. 2011;30(1):72-80.

20. Kent DL. Age-related macular degeneration: beyond anti-angiogenesis. Mol Vis. 2014;20:46-55.
21. Dallinger S, Findl O, Strenn K, Eichler HG, Wolzt M, Schmetterer L. Age dependence of choroidal blood flow. J Am Geriatr Soc. 1998;46 (4):484-7.

22. Lam AK, Chan ST, Chan H, Chan B. The effect of age on ocular blood supply determined by pulsatile ocular blood flow and color Doppler ultrasonography. Optom Vis Sci. 2003:80(4):305-11.

23. Grunwald JE, Metelitsina TI, Dupont JC, Ying GS, Maguire MG. Reduced foveolar choroidal blood flow in eyes with increasing AMD severity. Invest Ophthalmol Vis Sci. 2005;46(3):1033-8.

24. Coleman DJ, Silverman RH, Rondeau MJ, Lloyd HO, Khanifar AA, Chan RV. Age-related macular degeneration: choroidal ischaemia. Br J Ophthalmol. 2013;97(8):1020-3.

25. Ciulla TA, Harris A, Chung HS, Danis RP, Kagemann L, McNulty L, Pratt LM, Martin BJ. Color Doppler imaging discloses reduced ocular blood flow velocities in nonexudative age-related macular degeneration. Am J Ophthalmol. 1999;128(1):75-80

26. Berenberg TL, Metelitsina TI, Madow B, Dai Y, Ying GS, Dupont JC, Grunwald L, Brucker AJ, Grunwald JE. The association between drusen extent and foveolar choroidal blood flow in age-related macular degeneration. Retina. 2012;32(1):25-31.

27. Ames A 3rd, Li YY, Heher EC, Kimble CR. Energy metabolism of rabbit retina as related to function: high cost of Na+ transport. J Neurosci. 1992; 12(3):840-53.

28. Wang GL, Jiang BH, Rue EA, Semenza GL. Hypoxia-inducible factor 1 is a basic-helix-loop-helix-PAS heterodimer regulated by cellular $\mathrm{O} 2$ tension. Proc Natl Acad Sci U S A. 1995;92(12):5510-4.

29. Jaakkola P, Mole DR, Tian YM, Wilson MI, Gielbert J, Gaskell SJ, von Kriegsheim A, Hebestreit HF, Mukherji M, Schofield CJ, et al. Targeting of HIF-alpha to the von Hippel-Lindau ubiquitylation complex by O2-regulated prolyl hydroxylation. Science. 2001;292(5516):468-72.

30. Semenza GL. Hydroxylation of HIF-1: oxygen sensing at the molecular level. Physiology (Bethesda). 2004;19:176-82.

31. Semenza GL. Oxygen sensing, homeostasis, and disease. N Engl J Med. 2011;365(6):537-47.

32. Samardzija M, Caprara C, Heynen SR, Willcox DeParis S, Meneau I, Traber G, Agca C, von Lintig J, Grimm C. A mouse model for studying cone photoreceptor pathologies. Invest Ophthalmol Vis Sci. 2014:55(8):5304-13

33. Samardzija M, von Lintig J, Tanimoto N, Oberhauser V, Thiersch M, Reme CE, Seeliger M, Grimm C, Wenzel A. R91W mutation in Rpe65 leads to milder early-onset retinal dystrophy due to the generation of low levels of 11-cisretinal. Hum Mol Genet. 2008;17(2):281-92.

34. Mears AJ, Kondo M, Swain PK, Takada Y, Bush RA, Saunders TL, Sieving PA, Swaroop A. Nrl is required for rod photoreceptor development. Nat Genet. 2001:29(4):447-52

35. Haase VH, Glickman JN, Socolovsky M, Jaenisch R. Vascular tumors in livers with targeted inactivation of the von Hippel-Lindau tumor suppressor. Proc Natl Acad Sci U S A. 2001;98(4):1583-8.

36. Akimoto M, Filippova E, Gage PJ, Zhu X, Craft CM, Swaroop A. Transgenic mice expressing Cre-recombinase specifically in $\mathrm{M}$ - or S-cone photoreceptors. Invest Ophthalmol Vis Sci. 2004:45(1):42-7.

37. Ryan HE, Poloni M, McNulty W, Elson D, Gassmann M, Arbeit JM, Johnson RS. Hypoxia-inducible factor-1alpha is a positive factor in solid tumor growth. Cancer Res. 2000;60(15):4010-5.

38. Kast B, Schori C, Grimm C. Hypoxic preconditioning protects photoreceptors against light damage independently of hypoxia inducible transcription factors in rods. Exp Eye Res. 2016;146:60-71.

39. Lange C, Heynen SR, Tanimoto N, Thiersch M, Le YZ, Meneau I, Seeliger MW, Samardzija M, Caprara C, Grimm C. Normoxic activation of hypoxia-inducible factors in photoreceptors provides transient protection against light-induced retinal degeneration. Invest Ophthalmol Vis Sci. 2011;52(8):5872-80.

40. Madisen L, Zwingman TA, Sunkin SM, Oh SW, Zariwala HA, Gu H, Ng LL, Palmiter RD, Hawrylycz MJ, Jones AR, et al. A robust and high-throughput Cre reporting and characterization system for the whole mouse brain. Nat Neurosci. 2010;13(1):133-40.

41. Heynen SR, Tanimoto N, Joly S, Seeliger MW, Samardzija M, Grimm C. Retinal degeneration modulates intracellular localization of CDC42 in photoreceptors. Mol Vis. 2011:17:2934-46.

42. Caprara C, Thiersch M, Lange C, Joly S, Samardzija M, Grimm C. HIF1A is essential for the development of the intermediate plexus of the retinal vasculature. Invest Ophthalmol Vis Sci. 2011;52(5):2109-17. 
43. Ardeljan D, Meyerle CB, Agron E, Wang JJ, Mitchell P, Chew EY, Zhao J, Maminishkis A, Chan CC, Tuo J. Influence of TIMP3/SYN3 polymorphisms on the phenotypic presentation of age-related macular degeneration. Eur J Hum Genet. 2013:21(10):1152-7.

44. Vierkotten S, Muether PS, Fauser S. Overexpression of HTRA1 leads to ultrastructural changes in the elastic layer of Bruch's membrane via cleavage of extracellular matrix components. PLoS One. 2011;6(8):e22959.

45. Campochiaro PA. Molecular pathogenesis of retinal and choroidal vascular diseases. Prog Retin Eye Res. 2015;49:67-81.

46. Swaroop A, Kim D, Forrest D. Transcriptional regulation of photoreceptor development and homeostasis in the mammalian retina. Nat Rev Neurosci. 2010;11(8):563-76.

47. Roberts MR, Srinivas M, Forrest D, Morreale de Escobar G, Reh TA. Making the gradient: thyroid hormone regulates cone opsin expression in the developing mouse retina. Proc Natl Acad Sci U S A. 2006;103(16):6218-23.

48. Fruttiger M. Development of the retinal vasculature. Angiogenesis. 2007; 10(2):77-88.

49. Stone J, Itin A, Alon T, Pe'er J, Gnessin H, Chan-Ling T, Keshet E. Development of retinal vasculature is mediated by hypoxia-induced vascular endothelial growth factor (VEGF) expression by neuroglia. J Neurosci. 1995;15(7 Pt 1):4738-47.

50. Baird A, Esch F, Gospodarowicz D, Guillemin R. Retina- and eye-derived endothelial cell growth factors: partial molecular characterization and identity with acidic and basic fibroblast growth factors. Biochemistry. 1985; 24(27):7855-60.

51. Joly S, Lange C, Thiersch M, Samardzija M, Grimm C. Leukemia inhibitory factor extends the lifespan of injured photoreceptors in vivo. J Neurosci. 2008;28(51):13765-74.

52. Lange C, Caprara C, Tanimoto N, Beck S, Huber G, Samardzija M, Seeliger M, Grimm C. Retina-specific activation of a sustained hypoxia-like response leads to severe retinal degeneration and loss of vision. Neurobiol Dis. 2011; 41(1):119-30.

53. Sun Y, Liegl R, Gong Y, Buhler A, Cakir B, Meng SS, Burnim SB, Liu CH, Reuer T, Zhang $P$, et al. Sema3f Protects Against Subretinal Neovascularization In Vivo. EBioMedicine. 2017;18:281-7.

54. Lindblom P, Gerhardt H, Liebner S, Abramsson A, Enge M, Hellstrom M, Backstrom G, Fredriksson S, Landegren U, Nystrom HC, et al. Endothelial PDGF-B retention is required for proper investment of pericytes in the microvessel wall. Genes Dev. 2003;17(15):1835-40.

55. Betsholtz C. Insight into the physiological functions of PDGF through genetic studies in mice. Cytokine Growth Factor Rev. 2004;15(4):215-28.

56. Lindahl P, Johansson BR, Leveen P, Betsholtz C. Pericyte loss and microaneurysm formation in PDGF-B-deficient mice. Science. 1997; 277(5323):242-5.

57. Campochiaro PA. Ocular neovascularization. J Mol Med (Berl). 2013;91(3):311-21.

58. Andrae J, Gallini R, Betsholtz C. Role of platelet-derived growth factors in physiology and medicine. Genes Dev. 2008;22(10):1276-312.

59. Benjamin LE, Hemo I, Keshet EA. plasticity window for blood vessel remodelling is defined by pericyte coverage of the preformed endothelial network and is regulated by PDGF-B and VEGF. Development. 1998;125(9):1591-8.

60. Fruttiger M. Development of the mouse retinal vasculature: angiogenesis versus vasculogenesis. Invest Ophthalmol Vis Sci. 2002;43(2):522-7.

61. Hellstrom M, Kalen M, Lindahl P, Abramsson A, Betsholtz C. Role of PDGF-B and PDGFR-beta in recruitment of vascular smooth muscle cells and pericytes during embryonic blood vessel formation in the mouse. Development. 1999;126(14):3047-55.

62. Inoue $Y$, Yanagi $Y$, Matsuura $K$, Takahashi H, Tamaki Y, Araie M. Expression of hypoxia-inducible factor 1alpha and 2alpha in choroidal neovascular membranes associated with age-related macular degeneration. $\mathrm{Br} J$ Ophthalmol. 2007;91(12):1720-1.

63. Kim JH, Kim JR, Kang SW, Kim SJ, Ha HS. Thinner choroid and greater drusen extent in retinal angiomatous proliferation than in typical exudative age-related macular degeneration. Am J Ophthalmol. 2013;155(4):743-749, 749 e $741-742$

64. Kamei M, Hollyfield JG. TIMP-3 in Bruch's membrane: changes during aging and in age-related macular degeneration. Invest Ophthalmol Vis Sci. 1999; 40(10):2367-75.

65. Qi JH, Ebrahem Q, Moore N, Murphy G, Claesson-Welsh L, Bond M, Baker A, Anand-Apte B. A novel function for tissue inhibitor of metalloproteinases-3
(TIMP3): inhibition of angiogenesis by blockage of VEGF binding to VEGF receptor-2. Nat Med. 2003;9(4):407-15.

66. Macgregor AM, Eberhart CG, Fraig M, Lu J, Halushka MK. Tissue inhibitor of matrix metalloproteinase-3 levels in the extracellular matrix of lung, kidney, and eye increase with age. J Histochem Cytochem. 2009;57(3):207-13.

67. Weber BH, Vogt G, Pruett RC, Stohr H, Felbor U. Mutations in the tissue inhibitor of metalloproteinases-3 (TIMP3) in patients with Sorsby's fundus dystrophy. Nat Genet. 1994;8(4):352-6.

68. Lin RJ, Blumenkranz MS, Binkley J, Wu K, Vollrath D. A novel His158Arg mutation in TIMP3 causes a late-onset form of Sorsby fundus dystrophy. Am J Ophthalmol. 2006;142(5):839-48.

69. Okamoto N, Tobe T, Hackett SF, Ozaki H, Vinores MA, LaRochelle W, Zack DJ, Campochiaro PA. Transgenic mice with increased expression of vascular endothelial growth factor in the retina: a new model of intraretinal and subretinal neovascularization. Am J Pathol. 1997:151(1):281-91.

70. Ohno-Matsui K, Hirose A, Yamamoto S, Saikia J, Okamoto N, Gehlbach P, Duh EJ, Hackett S, Chang M, Bok D, et al. Inducible expression of vascular endothelial growth factor in adult mice causes severe proliferative retinopathy and retinal detachment. Am J Pathol. 2002;160(2):711-9.

71. Ida H, Tobe T, Nambu H, Matsumura M, Uyama M, Campochiaro PA. RPE cells modulate subretinal neovascularization, but do not cause regression in mice with sustained expression of VEGF. Invest Ophthalmol Vis Sci. 2003; 44(12):5430-7

72. Semenza GL. Oxygen-dependent regulation of mitochondrial respiration by hypoxia-inducible factor 1. Biochem J. 2007;405(1):1-9.

73. Punzo C, Kornacker K, Cepko CL. Stimulation of the insulin/mTOR pathway delays cone death in a mouse model of retinitis pigmentosa. Nat Neurosci. 2009;12(1):44-52.

74. Punzo C, Xiong W, Cepko CL. Loss of daylight vision in retinal degeneration: are oxidative stress and metabolic dysregulation to blame? J Biol Chem. 2012;287(3):1642-8.

75. Kurihara T, Westenskow PD, Gantner ML, Usui Y, Schultz A, Bravo S, Aguilar E, Wittgrove C, Friedlander MS, Paris LP, et al. Hypoxia-induced metabolic stress in retinal pigment epithelial cells is sufficient to induce photoreceptor degeneration. Elife. 2016;5:e14319.

76. Kurihara T, Kubota Y, Ozawa Y, Takubo K, Noda K, Simon MC, Johnson RS, Suematsu M, Tsubota K, Ishida S, et al. von Hippel-Lindau protein regulates transition from the fetal to the adult circulatory system in retina. Development. 2010;137(9):1563-71.

77. Zhao L, Ma W, Fariss RN, Wong WT. Minocycline attenuates photoreceptor degeneration in a mouse model of subretinal hemorrhage. microglial: inhibition as a potential therapeutic strategy. Am J Pathol. 2011;179(3):1265-77.

78. Geiger P, Barben M, Grimm C, Samardzija M. Blue light-induced retinal lesions, intraretinal vascular leakage and edema formation in the all-cone mouse retina. Cell Death Dis. 2015;6:e1985.

79. Frykman PK, Brown MS, Yamamoto T, Goldstein JL, Herz J. Normal plasma lipoproteins and fertility in gene-targeted mice homozygous for a disruption in the gene encoding very low density lipoprotein receptor. Proc Natl Acad Sci U S A. 1995:92(18):8453-7.

80. Heckenlively JR, Hawes NL, Friedlander M, Nusinowitz S, Hurd R, Davisson M, Chang B. Mouse model of subretinal neovascularization with choroidal anastomosis. Retina. 2003;23(4):518-22.

81. Hu W, Jiang A, Liang J, Meng H, Chang B, Gao H, Qiao X. Expression of VLDLR in the retina and evolution of subretinal neovascularization in the knockout mouse model's retinal angiomatous proliferation. Invest Ophthalmol Vis Sci. 2008;49(1):407-15.

82. Joyal JS, Sun Y, Gantner ML, Shao Z, Evans LP, Saba N, Fredrick T, Burnim S, Kim JS, Patel G, et al. Retinal lipid and glucose metabolism dictates angiogenesis through the lipid sensor Ffar1. Nat Med. 2016;22(4):439-45. 